\title{
Prothrombin Time
}

National Cancer Institute

\section{Source}

National Cancer Institute. Prothrombin Time. NCI Thesaurus. Code C62656.

A measurement of the clotting time of plasma recalcified in the presence of excess

tissue thromboplastin; it is a measure of the extrinsic pathway of coagulation. It is used

to determine the clotting tendency of blood, in the measure of warfarin dosage, liver

damage and vitamin $\mathrm{K}$ status. Factors measured are fibrinogen, prothrombin, and factors V, VII, and X. 